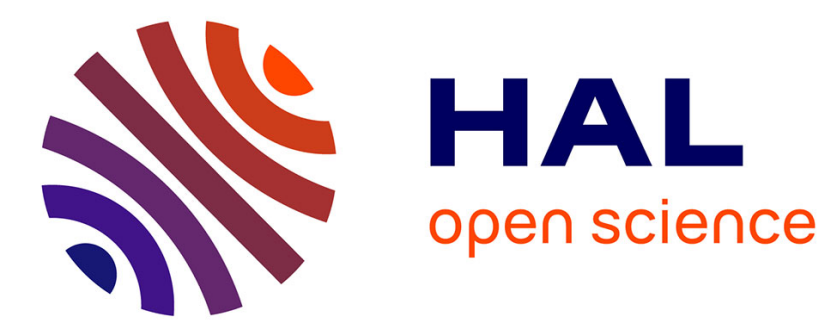

\title{
Murphy-Topel adjustment of the variance-covariance matrix of a two-step panel data model: Evidence from competition-fragility nexus in banking Ion Lapteacru
}

\section{- To cite this version:}

Ion Lapteacru. Murphy-Topel adjustment of the variance-covariance matrix of a two-step panel data model: Evidence from competition-fragility nexus in banking. 2016. hal-01337726

\author{
HAL Id: hal-01337726 \\ https://hal.science/hal-01337726
}

Preprint submitted on 27 Jun 2016

HAL is a multi-disciplinary open access archive for the deposit and dissemination of scientific research documents, whether they are published or not. The documents may come from teaching and research institutions in France or abroad, or from public or private research centers.
L'archive ouverte pluridisciplinaire HAL, est destinée au dépôt et à la diffusion de documents scientifiques de niveau recherche, publiés ou non, émanant des établissements d'enseignement et de recherche français ou étrangers, des laboratoires publics ou privés. 


\title{
larefíworking \\ Laborato ire d'Analyse et de Recherche en Économie et Finance Internationales \\ Murphy-Topel adjustment of the variance-covariance matrix of a two-step panel data model: Evidence from competition-fragility nexus in banking
}

\author{
Ion Lapteacru
}

LAREFI Working Paper N²016-08

2016

http://lare-efi.u-bordeaux4.fr

LAREFI

Université Montesquieu-Bordeaux IV Bâtiment Recherche Economie $-1^{\mathrm{er}}$ étage Avenue Léon Duguit - 33608 Pessac 


\section{AUTHORS}

Ion Lapteacru, LAREFI, Université Montesquieu Bordeaux IV

\section{NOTICES}

LAREFI Working Papers contain preliminary material and research results. They have been peer reviewed. They are circulated in order to stimulate discussion and critical comment; any opinions expressed are only those of the author(s).

Copyright LAREFI. All rights reserved. Sections of this material may be reproduced for personal and not-for-profit use without the express written permission of but with acknowledgment to LAREFI. To reproduce the material contained herein for profit 


\title{
Murphy-Topel adjustment of the variance-covariance matrix of a two-step panel data model: Evidence from competition-fragility nexus in banking
}

\author{
Ion Lapteacru \\ Larefi, Department of Economics, University of Bordeaux, Avenue Léon Duguit, 33608 \\ PESSAC, FRANCE, email: ion.lapteacru@u-bordeaux.fr, tel.: +33556842556, fax.: \\ $+33556848534$
}

\begin{abstract}
We develop the Murphy-Topel adjustment of the variance-covariance matrix for two-step panel data models. We apply it on the competition-fragility nexus in banking with different samples for two equations. Indeed, this issue is often observed in this field of research. A competition measure of banks is constructed for each country (first equation), whereas a risk measure is regressed on the entire sample of countries (second equation). Any statistical adjustment will only provide approximate results for the second equation, because of possible correlations between the results of both models. The Murphy-Topel method eventually seems to be more appropriate.
\end{abstract}

JEL classification: Banking, Murphy-Topel adjustment, competition, risk.

Keywords: C33, G21. 


\section{Introduction}

Many papers in economic empirical literature treat a subject with a two-step econometric model. The authors regress a first equation whose results are then applied in the computation of an explanatory variable that is used in the regression of a second equation. And many of them make these regressions independently of each other, considering therefore that this explanatory variable has no estimation error. Nevertheless, the errors of parameters from the first regression provide to this variable a random character and the values of parameters allow the determination of its expected value, which cannot be considered as an observed data unlike other explanatory variables. Consequently, since it depends on the regression results of the first model, the precision (the standard errors) of parameters of the second model must be adjusted.

Given this embedding of regressions and results, few authors merely bootstrap the standard errors of the second equation (for instance, Schaeck et al. 2009, Buch et al. 2013). However, this statistical procedure does not take into account the results of the first equation, neither its parameters nor its variance-covariance matrix, and does not consider a possible correlation between these results and those of the second equation, thereby providing approximate results. Murphy and Topel $(1985,2002)$ propose an adjustment of the variancecovariance matrix for the second model and therefore of its standard errors. The aim of the present paper is to develop this procedure for panel data models with different samples for the first and second equations and to apply it to the estimation of the competition-fragility relationship in banking.

This subject is widely studied in empirical banking literature and all studies are made on panel data. However, very few of them bootstrapped the standard errors and none made a precise adjustment with the Murphy-Topel approach. The importance of the subject and the difficulty to estimate correctly the standard errors of the second equation, namely different samples for regression equations, lead us to develop the Murphy-Topel adjustment of the variance-covariance matrix of two-step panel data models, which seems more appropriate.

\section{Two-step econometric model and Murphy-Topel variance-covariance matrix}

Two-step econometric model consists of two equations, where the parameters of the first equation will appear in the second equation and the precision of their estimation, that is, the variance-covariance matrix, interferes therefore in the precision of the second equation's parameters.

Let

Model 1: $y_{1}=f_{1}\left(\mathbf{x}_{1}, \boldsymbol{\alpha}\right)$

be the first equation, whose econometric results, that is, coefficients and variance-covariance matrix, are involved in the regression of the following second equation

Model 2: $y_{2}=f_{2}\left(\mathbf{x}_{1}, \mathbf{x}_{2}, \widehat{\boldsymbol{\alpha}}, \boldsymbol{\beta}\right)$,

where $\mathbf{x}_{i 1}$ and $\mathbf{x}_{i 2}$ are vectors of explanatory variables of the first and second models, respectively, and $\boldsymbol{\alpha}$ and $\boldsymbol{\beta}$ are vectors of parameters of model 1 and model 2, respectively. Vector $\boldsymbol{\beta}$ includes also the coefficient $\boldsymbol{\gamma}$ that connects to the second equation the explanatory variable computed with the parameters of the first equation.

Unlike many empirical studies that use two-step econometric models and consider the variables with coefficient $\boldsymbol{\gamma}$ as they contain observed data, one might consider them as estimators and adjust therefore the variance-covariance matrix of the second equation. Murphy and Topel (1985, 2002) proposes a full information maximum likelihood estimation with two-step procedure that consists to estimate, firstly, the parameters $\boldsymbol{\alpha}$ of model 1 by maximizing its likelihood function

$\ln L_{1}(\boldsymbol{\alpha})=\sum_{i} \ln f_{1}\left(y_{1 i} \mid \mathbf{x}_{1 i}, \boldsymbol{\alpha}\right)$ 
and, secondly, the parameters $\boldsymbol{\beta}$ of model 2 by maximizing the respective likelihood function

$\ln L_{2}(\widehat{\boldsymbol{\alpha}}, \boldsymbol{\beta})=\sum_{i} \ln f_{2}\left(y_{2 i} \mid \mathbf{x}_{1 i}, \mathbf{x}_{2 i}, \widehat{\boldsymbol{\alpha}}, \boldsymbol{\beta}\right)$,

where the embedded consistent estimator $\widehat{\boldsymbol{\alpha}}$ is treated as given. Greene (2012, p. 576) explains the reasons why one might proceed with two-step estimations. Among them, the easiness to formulate and to maximize the two separate log-likelihoods leads to choose this approach, instead of the maximisation of a complicated joint distribution function. Thus, Murphy and Topel $(1985,2002)$ show that if the regression results can be obtained with MLE, then the variance-covariance matrix of the second equation must be adjusted in the following way

$V_{2}^{*}=V_{2}+V_{2}\left[C V_{1} C^{\prime}-R V_{1} C^{\prime}-C V_{1} R^{\prime}\right] V_{2}$,

where

$V_{1}=\left[\sum_{i}\left(-\frac{\partial^{2} \ln f_{1, i}}{\partial \widehat{\boldsymbol{\alpha}} \partial \widehat{\boldsymbol{\alpha}}^{\prime}}\right)\right]^{-1}=\left[\sum_{i}\left(\frac{\partial \ln f_{1, i}}{\partial \widehat{\boldsymbol{\alpha}}}\right)\left(\frac{\partial \ln f_{1, i}}{\partial \widehat{\boldsymbol{\alpha}}^{\prime}}\right)\right]^{-1}$

is the variance-covariance matrix of model 1 ,

$V_{2}=\left[\sum_{i}\left(-\frac{\partial^{2} \ln f_{2, i}}{\partial \widehat{\boldsymbol{\beta}} \partial \widehat{\boldsymbol{\beta}}^{\prime}}\right)\right]^{-1}=\left[\sum_{i}\left(\frac{\partial \ln f_{2, i}}{\partial \widehat{\boldsymbol{\beta}}}\right)\left(\frac{\partial \ln f_{2, i}}{\partial \widehat{\boldsymbol{\beta}}^{\prime}}\right)\right]^{-1}$

is the variance-covariance matrix of model 2 when no adjustment is made, that is, when the constructed explanatory variable is considered with given observed data instead of computed econometric results, and

$C=\sum_{i}\left(-\frac{\partial^{2} \ln f_{2, i}}{\partial \widehat{\boldsymbol{\beta}} \partial \widehat{\boldsymbol{\alpha}}^{\prime}}\right)=\sum_{i}\left(\frac{\partial \ln f_{2, i}}{\partial \widehat{\boldsymbol{\beta}}}\right)\left(\frac{\partial \ln f_{2, i}}{\partial \widehat{\boldsymbol{\alpha}}^{\prime}}\right)$,

$R=\sum_{i}\left(\frac{\partial \ln f_{2, i}}{\partial \widehat{\boldsymbol{\beta}}}\right)\left(\frac{\partial \ln f_{1, i}}{\partial \widehat{\boldsymbol{\alpha}}^{\prime}}\right)$

are the matrices of cross products of first derivative vectors. Since the variance of the first derivative vector of the log-likelihood is the negative of the expected second derivative matrix, the two formulas for matrices $V_{1}, V_{2}$ and $C$ provide the same result. As the covariance of the two first derivative vectors, it is very likely that the matrix $R$ has all elements very close to zero.

\section{Application: competition-fragility nexus in banking}

There is some difficulty to develop the Murphy-Topel adjustment for panel data models with different samples, which it is often the case of studies on the competition-fragility relationship.

\subsection{Two-step panel data model}

At the first stage, one might estimate the bank competition measure. Let us take the following examples for the first equation, which are widely applied in banking empirical literature.

$1^{\text {st }}$ stage: Lerner index

The Lerner index is the mark-up of price over the bank's marginal cost:

$$
L_{i t}=\frac{p_{i t}-\frac{\partial C_{i t}}{\partial y_{i t}}}{p_{i t}}
$$

where $p_{i t}=T R_{i t} /\left(y_{1, i t}+y_{2, i t}+y_{3, i t}\right)$ is the average price of a bank $i$ 's output at time $t, C_{i t}$ is the bank's total cost and $y_{i t}$ is its output. Higher is the Lerner index, higher is the market power and less competitive banking institutions are. 
The econometric task is thus to estimate the marginal costs of banks, $\partial C_{i t} / \partial y_{i t}$. As in the most literature, we take three inputs, prices of which are $w_{j}$, and three outputs $y_{m}$ :

$$
\begin{aligned}
\ln \left(C_{i t} / w_{3, i t}\right)= & c_{0}+\alpha_{i}+\mu_{t}+\sum_{j=1}^{2} \beta_{j} \ln \left(w_{j, i t} / w_{3, i t}\right)+\sum_{m=1}^{3} \gamma_{m} \ln y_{m, i t} \\
& +\frac{1}{2} \sum_{k=1}^{2} \sum_{l=1}^{2} \varphi_{k l} \ln \left(w_{k, i t} / w_{3, i t}\right) \ln \left(w_{l, i t} / w_{3, i t}\right) \\
& +\sum_{m=1}^{3} \sum_{k=1}^{2} \chi_{m k} \ln \left(w_{k, i t} / w_{3, i t}\right) \ln y_{m, i t}+\frac{1}{2} \sum_{m=1}^{3} \sum_{s=1}^{3} \rho_{m s} \ln y_{m, i t} \ln y_{s, i t} \\
& +\sum_{m=1}^{3} \omega_{1 m} \ln y_{m, i t} \ln g d p_{t}+\sum_{m=1}^{3} \omega_{2 m} \ln y_{m, i t} g r g d p_{t}+\varepsilon_{i t},
\end{aligned}
$$

To control the effects of the business cycle, the real GDP, $g d p_{t}$, and/or the real GDP growth, $g r g d p_{t}$, can be considered in levels and/or in cross-product terms. The estimated coefficients of this equation are applied to compute the marginal cost:

$$
\begin{aligned}
m c_{i t} & =\frac{\partial C_{i t}}{\partial\left(y_{1, i t}+y_{2, i t}+y_{3, i t}\right)}=\left[\sum_{m=1}^{3} \gamma_{m}+\sum_{m=1}^{3} \sum_{k=1}^{2} \chi_{m k} \ln \left(w_{k, i t} / w_{3, i t}\right)+\sum_{m=1}^{3} \sum_{s=1}^{3} \rho_{m s} \ln y_{s}\right. \\
& \left.+\sum_{m=1}^{3} \omega_{1 m} \ln g d p_{t}+\sum_{m=1}^{3} \omega_{2 m} g r g d p_{t}\right] \times \frac{C_{i t}}{y_{1, i t}+y_{2, i t}+y_{3, i t}} .
\end{aligned}
$$

$1^{\text {st }}$ stage: Boone indicator

The Boone indicator, proposed by Boone (2008), is the elasticity of market share to marginal cost. Based on the idea that more efficient banks, that is, with lower marginal costs, gain higher market shares, this effect will be stronger in more competitive banking market. One needs to run the following econometric model:

$\ln m s_{i t}=\pi_{0}+\pi_{1 i}+v_{t}+\theta_{1} \ln m c_{i t}+\theta_{2} \ln m c_{i t} \times \ln m c_{i t}+\theta_{3} \ln m c_{i t} \times \ln g d p_{t}$

$$
+\theta_{4} \ln m c_{i t} \times g r g d p_{t}+\varepsilon_{i t}
$$

where $m s_{i t}$ stands for earning assets share for bank $i$ in year $t$. As the elasticity of market share to marginal cost, the Boone indicator is calculated as following:

Boone $_{i t}=\theta_{1}+2 \theta_{2} \ln m c_{i t}+\theta_{3} \ln g d p_{t}+\theta_{4} g r g d p_{t}$.

Since Boone might take negative values, higher values (or lower absolute values) imply less competitive behaviour.

$1^{\text {st }}$ stage: H-statistic

The H-statistic of Panzar and Rosse (1987) is the aggregate elasticity of banks' revenue to input prices. It can therefore be computed regressing the following translog revenue function of banks:

$$
\begin{aligned}
\ln T R_{i t} & =\mathrm{a}_{0}+\vartheta_{\mathrm{i}}+v_{t}+\sum_{j=1}^{3} \lambda_{j} \ln w_{j, i t}+\psi_{1} \ln T A_{i t}+\psi_{2} \ln \operatorname{Loan}_{i t}+\frac{1}{2} \sum_{k=1}^{3} \sum_{l=1}^{3} \kappa_{k l} \ln w_{k, i t} \ln w_{l, i t} \\
& +\sum_{k=1}^{3} \phi_{1 k} \ln w_{k, i t} \ln T A_{i t}+\sum_{k=1}^{3} \phi_{2 k} \ln w_{k, i t} \operatorname{Loan}_{i t}+\sum_{k=1}^{3} \phi_{3 k} \ln w_{k, i t} \ln g d p_{t} \\
& +\sum_{k=1}^{3} \phi_{4 k} \ln w_{k, i t} \operatorname{grgdp_{t}}+\varepsilon_{i t},
\end{aligned}
$$

where $T R_{i t}$ stands for total revenue of bank $i$ in year $t, T A_{i t}$ for total assets and $\operatorname{Loan}_{i t}$ for ratio of loans on total assets. As for the Lerner index, we consider three inputs for bank 
intermediation function. Usually in banking empirical literature, the use of $T A$ and Loan variables is to take into account the differences in size and business model, respectively, akin to De Bandt and Davis (2000), Bikker and Haaf (2002), Weill (2013). And as for previous two measures, the economic state variables are considered to control the business cycles. Thus, the H-statistic is equal to

$$
\begin{aligned}
H_{i t} & =\sum_{k=1}^{3} \frac{\partial T R_{i t}}{\partial w_{k, i t}} \times \frac{w_{k, i t}}{T R_{i t}}=\sum_{k=1}^{3} \lambda_{j}+\sum_{k=1}^{3} \sum_{l=1}^{3} \kappa_{k l} \ln w_{l, i t}+\sum_{k=1}^{3} \phi_{1 k} \ln T A_{i t}+\sum_{k=1}^{3} \phi_{2 k} \text { Loan }_{i t} \\
& +\sum_{k=1}^{3} \phi_{3 k} \ln g d p_{t}+\sum_{k=1}^{3} \phi_{4 k} g r g d p_{t} .
\end{aligned}
$$

H-statistic takes values between zero, monopoly or oligopoly situation, and one, perfectly competitive behaviour.

All regressions can be made individually on each country $k$ of the sample. However, since the risk measure cannot be computed for many of banks, namely for non-listed banks if a market-based measure is employed, the second equation is often regressed on entire sample of $N_{c}$ countries.

At the second stage, in order to estimate the relationship between bank competition and risk-taking, two different panel data models are considered in the banking literature:

$2^{\text {nd }}$ stage: linear relationship

$\operatorname{Risk}_{i, j, t}=\beta_{0}+\gamma_{1} B C_{i, j, t}+\sum_{k=1}^{n} \beta_{k} X_{k, i, j, t}+\sum_{l=n+1}^{m} \beta_{l} Y_{l, j, t}+\mu_{i}+\pi_{t}+\varepsilon_{i, j, t}$

$2^{\text {nd }}$ stage: non-linear relationship

$\operatorname{Risk}_{i, j, t}=\beta_{0}+\gamma_{1} B C_{i, j, t}+\gamma_{2} B C_{i, j, t}^{2}+\sum_{k=1}^{n} \beta_{k} X_{k, i, j, t}+\sum_{l=n+1}^{m} \beta_{l} Y_{l, j, t}+\mu_{i}+\pi_{t}+\varepsilon_{i, j, t}$

where $\operatorname{Risk}_{i, j, t}$ is a risk measure, $n$ is the number of bank-specific variables, $m-n$ is the number of country-specific variables, $B C_{i, j, t}$ and $X_{k, i, j, t}$ are, respectively, bank competition measure and bank-specific factor that controls for the $k$-th characteristic of bank $i$ at year $t$ in country $j$, and $Y_{l, j, t}$ is the country-specific factor that controls for the $l$-th characteristic of country $j$.

In order to determine the adjusted variance-covariance matrix $V_{2}^{*}$ of our risk equation, the variance-covariance matrices of the first and second equation $V_{1}$ and $V_{2}$, respectively, are extracted from the respective regressions and we must compute only the matrices $C$ and $R$.

The matrix $V_{1}$ is of dimension $l_{1} N_{c} \times l_{1} N_{c}$ and composed on the diagonal by variancecovariance matrices $V_{1, k}$ for each country $k\left(k=1, \ldots, N_{c}\right)$ and all other elements are zeros:

$V_{1}=\left(\begin{array}{cccc}V_{1,1} & 0 & \cdots & 0 \\ 0 & V_{1,2} & \cdots & 0 \\ \vdots & \vdots & \ddots & \vdots \\ 0 & 0 & \cdots & V_{1, N_{c}}\end{array}\right)$

The estimations of competition measures for all countries are therefore taken into consideration in the adjustment of the variance-covariance matrix $V_{2}$, which is of dimension $l_{2} \times l_{2} . l_{2}$ and $l_{1}$ are the size of vectors $\mathbf{x}_{2}$ and $\mathbf{x}_{1}$, respectively. These vectors of explanatory variables include also the intercept and the time fixed effects.

The difficulty of computation of matrices $C$ and $R$ is the difference between samples of two equations. They are determined as cross "products", for matrix $R$, or cross derivations, for matrix $C$, between the single sample of the second equation and the bank sample of each country. The computation of the elements $r[i, j]$ and $c[i, j]$ of matrices $R$ and $C$, respectively, are explained in next sub-section. 


\subsection{Murphy-Topel adjustment of the variance-covariance matrix of the risk equation}

For the first panel data model (eq. 8b, for the Lerner index, eq. 9 for the Boone indicator, and eq. 11 for the H-statistic), the likelihood is formulated for each country $k$ of the sample.

$$
\begin{aligned}
\ln f_{1, k, i}= & -\frac{1}{2}\left\{\frac{1}{\sigma e_{1, k}^{2}}\left[\sum_{t=1}^{T_{1, k, i}} \varepsilon_{1, k, i t}^{2}-\frac{\sigma e_{1, k}^{2}}{\sigma e_{1, k}^{2}+T_{1, k, i} \sigma u_{1, k}^{2}}\left(\sum_{t=1}^{T_{1, k, i}} \varepsilon_{1, k, i t}\right)^{2}\right]+\ln \left(1+T_{1, k, i} \frac{\sigma u_{1, k}^{2}}{\sigma e_{1, k}^{2}}\right)\right\} \\
& -\frac{1}{2}\left\{T_{1, k, i} \ln \left(2 \pi \sigma e_{1, k}^{2}\right)\right\}
\end{aligned}
$$

$k$ ranges from 1 to $N_{c} . \sigma e_{1, k}^{2}$ and $\sigma u_{1, k}^{2}$ are the variances of residuals and individual effects, respectively, for each panel data regression $k . \varepsilon_{1, k, i t}$ are residuals of this regression and $T_{1, k, i}$ number of observations for the bank $i$. The log-likelihood of the second model takes therefore the following form

$$
\begin{aligned}
\ln f_{2, i}= & -\frac{1}{2}\left\{\frac{1}{\sigma e_{2}^{2}}\left[\sum_{t=1}^{T_{2, i}} \varepsilon_{2, i t}^{2}-\frac{\sigma e_{2}^{2}}{\sigma e_{2}^{2}+T_{2, i} \sigma u_{2}^{2}}\left(\sum_{t=1}^{T_{2, i}} \varepsilon_{2, i t}\right)^{2}\right]+\ln \left(1+T_{2, i} \frac{\sigma u_{2}^{2}}{\sigma e_{2}^{2}}\right)\right\} \\
& -\frac{1}{2}\left\{T_{2, i} \ln \left(2 \pi \sigma e_{2}^{2}\right)\right\},
\end{aligned}
$$

where $\sigma e_{2}^{2}$ and $\sigma u_{2}^{2}$ are the variances of residuals and of individual effects, respectively. $\varepsilon_{2, i t}$ are residuals of this regression and $T_{2, i}$ number of observations for the bank $i$.

To compute the elements of matrices $R$ and $C$, we determine the following derivatives:

For the first equation:

$\frac{\partial \ln f_{1, k, i}}{\partial \widehat{\boldsymbol{\alpha}}_{k}}=\frac{1}{\sigma e_{1, k}^{2}}\left[\sum_{t=1}^{T_{1, k, i}} \varepsilon_{1, k, i t} \mathbf{x}_{1, k, i t}-\frac{\sigma e_{1, k}^{2}}{\sigma e_{1, k}^{2}+T_{1, k, i} \sigma u_{1, k}^{2}}\left(\sum_{t=1}^{T_{1, k, i}} \varepsilon_{1, k, i t}\right)\left(\sum_{t=1}^{T_{1, k, i}} \mathbf{x}_{1, k, i t}\right)\right]$

For the second equation:

$\frac{\partial \ln f_{2, i}}{\partial \widehat{\boldsymbol{\beta}}}=\frac{1}{\sigma e_{2}^{2}}\left[\sum_{t=1}^{T_{2, i}} \varepsilon_{2, i t} \mathbf{x}_{2, i t}-\frac{\sigma e_{2}^{2}}{\sigma e_{2}^{2}+T_{2, i} \sigma u_{2}^{2}}\left(\sum_{t=1}^{T_{2, i}} \varepsilon_{2, i t}\right)\left(\sum_{t=1}^{T_{2, i}} \mathbf{x}_{2, i t}\right)\right]$

Consequently, the elements of $R$ matrix for each country $k$ are

$$
\begin{array}{r}
r 0\left[k, l_{2}, l_{1}\right]=\sum_{i=1}^{N_{2}}\left\{\frac{1}{\sigma e_{2}^{2}}\left[\sum_{t=1}^{T_{2, i}} \varepsilon_{2, k, i t} \mathbf{x}\left[l_{2}\right]_{2, k, i t}-\frac{\sigma e_{2}^{2}}{\sigma e_{2}^{2}+T_{2, i} \sigma u_{2}^{2}}\left(\sum_{t=1}^{T_{2, i}} \varepsilon_{2, k, i t}\right)\left(\sum_{t=1}^{T_{2, i}} \mathbf{x}\left[l_{2}\right]_{2, k, i t}\right)\right]\right. \\
\left.\times \frac{1}{\sigma e_{1, k}^{2}}\left[\sum_{t=1}^{T_{1, k, i}} \varepsilon_{1, k, i t} \mathbf{x}\left[l_{1}\right]_{1, k, i t}-\frac{\sigma e_{1, k}^{2}}{\sigma e_{1, k}^{2}+T_{1, k, i} \sigma u_{1, k}^{2}}\left(\sum_{t=1}^{T_{1, k, i}} \varepsilon_{1, k, i t}\right)\left(\sum_{t=1}^{T_{1, k, i}} \mathbf{x}\left[l_{1}\right]_{1, k, i t}\right)\right]\right\},(18)
\end{array}
$$

where $N_{2}$ is the number of banks of the second model. Finally, the matrix $R$ has elements $r[i, j]=r 0\left[k, l_{2}, l_{1}\right]$, where $i=l_{2}$ and $j=k \times l_{1}$.

Besides the matrix $R$, the results of the first equation are also considered in the second one with the matrix $C$. Since we have two versions of the risk equation, this second derivative considers only $B C$ variable for the linear relationship equation (eq. 13a) and both $B C$ and $B C^{2}$ variables for non-linear relationship equation (eq. 13b) as follows:

For a liner model:

- The derivative of the $B C$ variable with respect to parameters of the first model 


$$
\begin{aligned}
c 0\left[k, 1, l_{1}\right]= & -\sum_{i=1}^{N_{2}}\left\{\frac { 1 } { \sigma e _ { 2 } ^ { 2 } } \left[\sum_{t=1}^{T_{2, i}}\left(\varepsilon_{2, k, i t}-\gamma_{1} B C_{k, i t}\right) \mathbf{x}^{\prime}\left[l_{1}\right]_{2, k, i t}\right.\right. \\
& \left.\left.-\frac{\sigma e_{2}^{2}}{\sigma e_{2}^{2}+T_{2, i} \sigma u_{2}^{2}}\left(\sum_{t=1}^{T_{2, i}} \varepsilon_{2, k, i t}-\gamma_{1} \sum_{t=1}^{T_{2, i}} B C_{k, i t}\right)\left(\sum_{t=1}^{T_{2, i}} \mathbf{x}^{\prime}\left[l_{1}\right]_{2, k, i t}\right)\right]\right\},
\end{aligned}
$$

- The derivative of other variables of the second equation with respect to parameters of the first model

$$
\begin{aligned}
c 0\left[k, l_{2}, l_{1}\right]= & -\sum_{i=1}^{N_{2}}\left\{\frac { 1 } { \sigma e _ { 2 } ^ { 2 } } \left[\sum_{t=1}^{T_{2, i}}-\gamma_{1} \mathbf{x}^{\prime}\left[l_{1}\right]_{2, k, i t} \mathbf{x}\left[l_{2}\right]_{2, k, i t}\right.\right. \\
& \left.\left.-\frac{\sigma e_{2}^{2}}{\sigma e_{2}^{2}+T_{2, i} \sigma u_{2}^{2}}\left(\sum_{t=1}^{T_{2, i}}-\gamma_{1} \mathbf{x}^{\prime}\left[l_{1}\right]_{2, k, i t}\right)\left(\sum_{t=1}^{T_{2, i}} \mathbf{x}\left[l_{2}\right]_{2, k, i t}\right)\right]\right\},
\end{aligned}
$$

For a non-linear model:

- The derivative of the $B C$ variable with respect to parameters of the first model

$$
\begin{aligned}
c 0\left[k, 1, l_{1}\right]= & -\sum_{i=1}^{N_{2}}\left\{\frac { 1 } { \sigma e _ { 2 } ^ { 2 } } \left[\sum_{t=1}^{T_{2, i}}\left(\varepsilon_{2, k, i t}+\left(-\gamma_{1}-2 \gamma_{2} B C_{k, i t}\right) B C_{k, i t}\right) \mathbf{x}^{\prime}\left[l_{1}\right]_{2, k, i t}\right.\right. \\
& -\frac{\sigma e_{2}^{2}}{\sigma e_{2}^{2}+T_{2, i} \sigma u_{2}^{2}}\left(\left(\sum_{t=1}^{T_{2, i}}\left(-\gamma_{1}-2 \gamma_{2} B C_{k, i t}\right) \mathbf{x}^{\prime}\left[l_{1}\right]_{2, k, i t}\right)\left(\sum_{t=1}^{T_{2, i}} B C_{k, i t}\right)\right. \\
& \left.\left.\left.+\left(\sum_{t=1}^{T_{2, i}} \varepsilon_{2, k, i t}\right)\left(\sum_{t=1}^{T_{2, i}} \mathbf{x}^{\prime}\left[l_{1}\right]_{2, k, i t}\right)\right)\right]\right\},
\end{aligned}
$$

- The derivative of the $B C^{2}$ variable with respect to parameters of the first model

$$
\begin{aligned}
c 0\left[k, 2, l_{1}\right]= & -\sum_{i=1}^{N_{2}}\left\{\frac { 1 } { \sigma e _ { 2 } ^ { 2 } } \left[\sum_{t=1}^{T_{2, i}}\left(2 B C_{k, i t} \varepsilon_{2, k, i t}+\left(-\gamma_{1}-2 \gamma_{2} B C_{k, i t}\right) B C_{k, i t}^{2}\right) \mathbf{x}^{\prime}\left[l_{1}\right]_{2, k, i t}\right.\right. \\
& -\frac{\sigma e_{2}^{2}}{\sigma e_{2}^{2}+T_{2, i} \sigma u_{2}^{2}}\left(\left(\sum_{t=1}^{T_{2, i}}\left(-\gamma_{1}-2 \gamma_{2} B C_{k, i t}\right) \mathbf{x}^{\prime}\left[l_{1}\right]_{2, k, i t}\right)\left(\sum_{t=1}^{T_{2, i}} B C_{k, i t}^{2}\right)\right. \\
& \left.\left.\left.+\left(\sum_{t=1}^{T_{2, i}} \varepsilon_{2, k, i t}\right)\left(\sum_{t=1}^{T_{2, i}} 2 B C_{k, i t} \mathbf{x}^{\prime}\left[l_{1}\right]_{2, k, i t}\right)\right)\right]\right\},
\end{aligned}
$$

and the derivative of other variables of the second equation with respect to parameters of the first model is the same equation (19b). The matrix $C$ has the elements $c[i, j]=c 0\left[k, l_{2}, l_{1}\right]$, where $i=l_{2}$ and $j=k \times l_{1}$, in both cases.

The difficulty to construct the matrices $R$ and $C$ is the difference in sample size of two equations: the first equation is regressed for each country $k$ and the second equation for entire sample of countries. To overcome it, we transformed the explanatory variables, $\mathbf{x}\left[l_{2}\right]_{2, k, i t}$, and the error term, $\varepsilon_{2, k, i t}$, of the second equation as that each country of the sample has its own 
variables. Each $k$ variable (or error term) takes therefore its own values if they correspond to country $k$ and zero otherwise.

The vector $\mathbf{x}^{\prime}\left[l_{1}\right]_{2}$ is the derivative of bank competition measure $B C$, estimated in the first step, with respect to parameters $l_{1}$ of the first equation. The index 2 signifies that this vector is obtained from the derivative of the log-likelihood of the second equation. The derivation is firstly made with respect to parameters of the explanatory variables and then with respect to parameters of fixed time effects and intercept. $\mathbf{x}^{\prime}\left[l_{1}\right]_{2}$ vector is therefore individual for each of our three non-structural competition measures:

- For the Lerner index, based on equations (8a)-(8c), and the definition of the average price of bank output

$$
\begin{aligned}
\mathbf{x}^{\prime}\left[l_{1}\right]_{2, k, i t}=[ & 0,0,-C_{k, i t} / T R_{k, i t},-C_{k, i t} / T R_{k, i t},-C_{k, i t} / T R_{k, i t}, 0,0,-C_{k, i t} / T R_{k, i t} \\
& \times \ln \left(w_{1, k, i t} / w_{3, k, i t}\right),-C_{k, i t} / T R_{k, i t} \times \ln \left(w_{1, k, i t} / w_{3, k, i t}\right),-C_{k, i t} / T R_{k, i t} \\
& \times \ln \left(w_{1, k, i t} / w_{3, k, i t}\right), 0,-C_{k, i t} / T R_{k, i t} \times \ln \left(w_{2, k, i t} / w_{3, k, i t}\right),-C_{k, i t} / T R_{k, i t} \\
& \times \ln \left(w_{2, k, i t} / w_{3, k, i t}\right),-C_{k, i t} / T R_{k, i t} \times \ln \left(w_{2, k, i t} / w_{3, k, i t}\right),-C_{k, i t} / T R_{k, i t} \\
& \times\left(\ln y_{1, k, i t}+\ln y_{1, k, i t}\right),-C_{k, i t} / T R_{k, i t} \times\left(\ln y_{1, k, i t}+\ln y_{2, k, i t}\right),-C_{k, i t} / T R_{k, i t} \\
& \times\left(\ln y_{1, k, i t}+\ln y_{3, k, i t}\right),-C_{k, i t} / T R_{k, i t} \times\left(\ln y_{2, k, i t}+\ln y_{2, k, i t}\right),-C_{k, i t} / T R_{k, i t} \\
& \times\left(\ln y_{2, k, i t}+\ln y_{3, k, i t}\right),-C_{k, i t} / T R_{k, i t} \times\left(\ln y_{3, k, i t}+\ln y_{3, k, i t}\right),-C_{k, i t} / T R_{k, i t} \\
& \times \ln g d p_{k, i t},-C_{k, i t} / T R_{k, i t} \times \ln g d p_{k, i t},-C_{k, i t} / T R_{k, i t} \\
& \times \ln g d p_{k, i t},-C_{k, i t} / T R_{k, i t} \times g d p g r_{k, i t},-C_{k, i t} / T R_{k, i t} \\
& \times g d p g r_{k, i t},-C_{k, i t} / T R_{k, i t} \times g d p g r_{k, i t}, \underbrace{0, \ldots, 0}_{t e}, 0]
\end{aligned}
$$

The size of this vector is the same as that of the explanatory variables of equation (8b), that is, $27+t e$, and includes 26 explanatory variables, te time fixed effects and 1 intercept.

- For the Boone indicator, based on equations (9) and (10)

$\mathbf{x}^{\prime}\left[l_{1}\right]_{2, k, i t}=[1,2 \ln m c_{k, i t}, \ln g d p_{k, i t}, g d p g r_{k, i t}, \underbrace{0, \ldots, 0}_{t e}, 0]$

The size of this vector is the same as that of the explanatory variables of equation (9), that is, $5+t e$, and includes 4 explanatory variables, te time fixed effects and 1 intercept.

- For the H-statistic, based on equations (11) and (12)

$$
\begin{aligned}
\mathbf{x}^{\prime}\left[l_{1}\right]_{2, k, i t}=\left[\begin{array}{rl}
1,1,1,0,0, \ln w_{1, k, i t}+\ln w_{1, k, i t}, \ln w_{1, k, i t}+\ln w_{2, k, i t}, \ln w_{1, k, i t}+\ln w_{3, k, i t}, \ln w_{2, k, i t} \\
+
\end{array}\right. \\
+\ln w_{2, k, i t}, \ln w_{2, k, i t}+\ln w_{3, k, i t}, \ln w_{3, k, i t}+\ln w_{3, k, i t}, \ln T A_{k, i t}, \ln T A_{k, i t}, \\
\\
\quad g d p g A_{k, i t}, \operatorname{Loan}_{k, i t}, \operatorname{Loan}_{k, i t}, \operatorname{Loan}_{k, i t}, \ln g d p_{k, i t}, \ln g d p_{k, i t}, \ln g d p_{k, i t}, g d p g r_{k, i t}, \underbrace{0, \ldots, 0}_{t e}, 0]
\end{aligned}
$$

The size of this vector is the same as that of the explanatory variables of equation (11), that is, $24+t e$, and includes 23 explanatory variables, te time fixed effects and 1 intercept.

\section{Conclusion}

In this paper, we developed the Murphy-Topel adjustment of the variance-covariance matrix of a two-step panel data model and for different samples of two equations, and we applied it on the example of competition-stability relationship in banking. This subject is widely studied in banking empirical literature and this econometric issue is therefore present. Because of possible correlations between the results of both models, the Murphy-Topel method eventually seems to be more appropriate than any statistical (numerical adjustment) as the bootstrapping procedure. 


\section{References}

Bikker, J. A. and K. Haaf (2002) "Competition, concentration and their relationship: an empirical analysis of the banking industry”, Journal of Banking and Finance 26, 21912214.

Boone, J. (2008) “A new way to measure competition” The Economic Journal 118, 12451261.

Buch, C. M., Koch, C. T. and M. Koetter (2013) "Do Banks Benefit from Internationalization? Revisiting the Market Power-Risk Nexus" Review of Finance 17, 1401-1435.

De Bandt, O. and E. Davis (2000) "Competition, contestability and market structure in European banking sector on the eve of EMU”, Journal of Banking and Finance 24, 10451066.

Greene, W. H. (2012) “Econometric Analysis”. Seventh edition. International edition. Pearson.

Murphy, K. and R. Topel (1985) "Estimation and Inference in Two Step Econometric Models” Journal of Business and Economic Statistics 3, 370-379.

Murphy, K. and R. Topel (2002) "Estimation and Inference in Two Step Econometric Models” Journal of Business and Economic Statistics 20, 88-97.

Panzar, J. and J. Rosse, (1987) “Testing for “monopoly” equilibrium”, Journal of Industrial Economics 35, 443-456.

Schaeck, K., Cihak, M. and S. Wolfe (2009) “Are competitive banking systems more stable?” Journal of Money, Credit and Banking 41, 711-734.

Weill, L. (2013) “Bank competition in the EU: How has it evolved?”, Journal of International Financial Markets, Institutions and Money 26, 100-112. 


\section{RECENT LAREFI WORKING PAPERS}

\section{For earlier LAREFI Working Papers, please go to http://lare-efi.org.u-bordeaux4.fr}

\section{All Discussion Papers can be downloaded free of charge}

CR16-EFI07 Faure, P-H., "Le bitcoin peut-il être assimilé à une monnaie ? Un examen à partir des différentes grilles de lecture de la science économique"

CR16-EFI06 Lapteacru, I., "Convergence of bank competition in Central and Eastern European countries : Does ownership matter ?"

CR16-EFI05 Lapteacru, I., "On the consistency of the Z-score to measure the bank risk"

CR16-EFI04 Lapteacru, I., "Income and funding structures, banking regulation and bank risk-taking : The role of ownership in Central and Eastern European banks"

CR16-EFI03 Humblot, T., "Distance et accès au crédit sous Bâle III"

CR16-EFI02 Berthoumieu, J. and V. Lamani, "Vertical Differentiation, Uncertainty, Product R\&D and Policy Instruments in a North-South Duopoly"

CR16-EFI01 Raffestin, L., "Foreign exchange investment rules and endogenous currency crashes"

CR15-EFI05 Berthoumieu,J., "Technology Diffusion via Patent Collaborations : The Case of European Integration"

CR15-EFI04 Bouet, A. and A-G. Vaubourg, "Financial Constraints and International Trade with Endogenous Mode of Competition"

CR15-EFI03 Lahet, D. and A-G. Vaubourg, "Banks' shareholding in multilateral trading facilities : A two-sided market perspective"

CR15-EFI02 Berthoumieu, J., "Policy Instruments, Patents and International Technology Diffusion in a North-South Duopoly"

CR15-EFI01 Dupuy, L., "International trade and structural change : a dynamic model of weak sustainability" 